\title{
Receptive Field Analysis and Orientation Selectivity of Postsynaptic Potentials of Simple Cells in Cat Visual Cortex
}

\author{
X. Pei, ${ }^{1}$ T. R. Vidyasagar, ${ }^{1,2}$ M. Volgushev, ${ }^{1,3}$ and O. D. Creutzfeldt1,a \\ 'Department of Neurobiology, Max Planck Institute for Biophysical Chemistry, D-3400 Göttingen, Germany, ${ }^{2}$ Division of \\ Neuroscience, John Curtin School of Medical Research, Australian National University, Canberra, A.C.T. 2601, Australia, \\ and ${ }^{3}$ institute of Higher Nervous Activity and Neurophysiology, Russian Academy of Sciences, Moscow 117865, Russia
}

\begin{abstract}
Postsynaptic potentials (PSPs) were recorded from cat striate cortical cells by the whole-cell in vivo recording technique using patch-clamp electrodes. EPSPs and IPSPs evoked by flashing bars on the receptive field at different positions and orientations revealed the spatial structure of the excitatory and inhibitory inputs. The elongation of the excitatory input field (length:width ratio) was found to be minimal (mean ratio of 1.7 ) and much lower than those reported for spike discharges. Two-dimensional receptive field response profiles of early PSPs were recorded by flashing a small spot of light over a square matrix covering the receptive field. These recordings also showed only mild degrees of elongations of the receptive field. Such elongations could be the result of either an excitatory input from the geniculate that is already biassed for orientation or an excitatory convergence from a limited number of LGN fields arranged in a row.
\end{abstract}

In most first-order cells, we found that inhibition was contributing significantly to orientation selectivity. Often prominent IPSPs could be evoked by stimuli of nonoptimum orientations. Presence of inhibition could also be inferred by the way that EPSPs were sharply cut off by inhibition. When the amplitude of an EPSP was measured at different latencies after its onset, the EPSP was found to be very broadly tuned to orientation at the beginning, but showing increasing orientation selectivity with time. It is proposed that this progressive development of orientation selectivity is due to (1) inhibitory inputs arriving after the first wave of excitation, (2) intracortical excitatory inputs from other cells tuned to similar orientations, and (3) voltage-sensitive mechanisms such as NMDA channels.

[Key words: visual cortex, receptive field, orientation selectivity, postsynaptic potentials, EPSP, IPSPI

The structures of the discharge zones of visual striate cortical neurons differ strikingly from the receptive field (RF) structures of the primary afferent fibers to the cortex from the LGN. Cells in the LGN have concentric and nearly circular antagonistic

\footnotetext{
Received Nov. 30, 1993; revised Apr. 12, 1994; accepted May 26, 1994.

M.V. was supported by Alexander von Humboldt Foundation and Max-Planck Society. X.P. was supported by Max-Planck Society and Garduiert Kellege of Goettingen University. We thank Dr. H.-C. Nothdurft for comments on the manuscript.

Correspondence should be addressed to T. R. Vidyasagar at the above Australian address.

a Deceased in January 1992.

Copyright (c) 1994 Society for Neuroscience $0270-6474 / 94 / 147130-11 \$ 05.00 / 0$
}

RF subregions (Rodieck and Stone, 1965), whereas discharge zones of cortical neurons, especially those of simple cells, are usually elongated and show a large variety of spatial arrangements. The responses of cortical neurons are also markedly orientation sensitive when tested with oriented stimuli, whereas LGN cells are either not sensitive to orientation or exhibit only an orientation bias (Daniels et al., 1977; Vidyasagar and Urbas, 1982; Shou and Leventhal, 1989). It has been suggested that the RF of a simple cell is formed by the convergence of a number of LGN fibers whose RF centers are aligned along a common axis, which becomes the axis of optimal orientation for the cell (Hubel and Wiesel, 1962). Simple cells have spatially separable ON and OFF discharge zones and the ratio of the elongation of a discharge zone (length:width) has been reported to range from 1.7 to 12 (Jones and Palmer, 1987). However, these values are likely to be the sum of the contributions of both the primary input from the LGN and intracortical excitation and inhibition. Spatiotemporal distribution of excitatory and inhibitory responses elicited by static and moving stimuli have in fact showed interactions between subfields (Palmer and Davis, 1981).

Suppression and facilitation effects in visual cortical responses have been studied using extracellular recording techniques (Blakemore and Tobin, 1972; Maffei and Fiorentini, 1976; Nelson and Frost, 1978; Heggelund, 1981; Bonds, 1989). But it is not possible to separate the contribution of excitatory and inhibitory inputs to a cell by studying the spike responses. For example, a decrease in the spike discharge may be due to either a decrease of excitatory input or an increase of inhibitory input or may be a result of both. Any facilitation effect may be due to an additional excitatory input to the recorded neuron or the result of a reduction of inhibition (disinhibition). The final output as spikes results from a balance of the interaction of the EPSPs and IPSPs and a threshold operation. Although the use of conditioning stimuli (Bishop et al., 1973; Heggelund, 1981) and pharmacological techniques (Sillito, 1975, 1980; Tsumoto, 1979; Eysel, 1992) helped to reveal inhibition and subthreshold excitatory synaptic activities, they inevitably introduce new interactions between the recorded cell and other cells in its surroundings.

Intracellular recording is the only technique at the moment that helps one to examine the subthreshold synaptic activities that produce inhibition and excitation. Despite much effort and progress over the past 25 years (Creutzfeldt et al., 1968, 1974, 1988; Dreifuss et al., 1968; Ferster and Lindström, 1983; Ferster, 1986; Douglas et al., 1988, 1991; Berman et al., 1989, 1991; Douglas and Martin, 1991), the cxtremc difficulty of intracellular recordings in vivo using classical fine-tipped micropipettes, 
together with problems of interpreting the data (Martin, 1988), have restricted the number of such studies. Furthermore, the limited time available for reliable recordings with each cell has restricted the studies to the use of moving stimuli, which are very inadequate to delineate the detailed structure of the input fields, because such stimuli can induce extensive spatiotemporal and intracortical interactions.

In this study, we recorded postsynaptic potentials in simple cells using the in vivo whole-cell recording technique (Pei et al., 1991; Ferster and Jagadeesh, 1992) with electrodes that are usually used for patch clamping (Sakmann and Neher, 1983). It is possible by this method to obtain reliable and stable recordings from the striate cortex for extended periods of 1-2 hr (Pei et al., 1991). Therefore, we were able to use both flashing and moving stimuli to analyze RF structures of excitatory and inhibitory synaptic events. Special attention was paid to the short latency excitatory and inhibitory potentials evoked by different flashing stimuli. The short latency excitatory responses are likely to result mainly from the primary LGN input to cortical cells and can provide a picture of the excitatory input to cortical cells before they are acted upon by intracortical excitation and inhibition. Our aim was to relate the orientation sensitivity of a cell to the receptive field structure of its inputs. The results have been published in preliminary form (Pei et al., 1992).

\section{Materials and Methods}

Preparations. Details of our general preparation and recording procedures are given in earlier publications (Pei et al., 1991; Volgushev et al., 1993). Briefly, adult cats $(2.0-4.5 \mathrm{~kg})$ bred in the department's animal house were anesthetized with ketamine hydrochloride intramuscularly (Ketanest, Parke-Davis, Berlin; $25 \mathrm{mg} / \mathrm{kg}$, i.m.) or with pentobarbitone sodium (Nembutal, Sanofi, Ceva; $35-40 \mathrm{mg} / \mathrm{kg}$ i.p.). Following tracheal and venous cannulations and bilateral cervical sympathectomy, muscle relaxation with gallamine triethiodide (Flaxedil) and artificial respiration were started after stable anesthesia with complete analgesia was achieved. Anesthesia was maintained on intravenous infusion of 3-4 $\mathrm{mg} / \mathrm{kg} / \mathrm{hr}$ pentobarbital (Nembutal, Sanofi, Ceva) without nitrous oxide or on $1-2 \mathrm{mg} / \mathrm{kg} / \mathrm{hr}$ Nembutal with a gas mixture of $\mathrm{N}_{2} \mathrm{O}: \mathrm{O}_{2}: \mathrm{CO}_{2}(70$ : 29.2:0.8). Paralysis was maintained with intravenous infusion of Flaxedil $(8 \mathrm{mg} / \mathrm{kg} / \mathrm{hr})$ in Ringer's solution. All wound edges and pressure points were treated with a local anesthetic (xylocaine). Since barbiturates are known to have an impact on GABAergic system, it may be argued that our use of this anesthetic has affected our results seriously. While this is an inevitable compromise for the sake of animal welfare, we have noticed little significant difference in results between our two anesthetic regimes that differed markedly in their barbiturate concentrations.

The animal's head was securely fixed in a stereotaxic frame. End-tidal $\mathrm{CO}_{2}$ was adjusted to around $3.6 \%(3.5-4.0 \%)$ and body temperature was maintained around $37-38^{\circ} \mathrm{C}$. The ECG was continuously monitored, and the absence of heart rate alteration during squeezing of the pinna was tested every few hours. The EEG was also monitored regularly. The hydraulically driven microelectrode holder (David Kopf Instruments) was directly mounted onto the skull with scrcws and dental cement. Brain pulsations were kept to a minimum by making a bilateral pneumothorax and by suspending the animal on the second thoracic vertebra. A craniotomy ( $5 \mathrm{~mm}$ diameter) was done over area 17 of the visual cortex centered at P4/Ll (Horsley-Clark), and a brass cylinder (20 mm diameter) was cemented over it. A small hole was cut into the dura just large enough to let an electrode in. After positioning the electrode, $2-3 \%$ agar was poured into the chamber.

The nictitating membranes were retracted and the pupils were dilated with topical application of $5 \%$ Neo-Synephrine and $1 \%$ atropine sulfate. Contact lenses of suitable radii were applied for correcting refraction. The position of the optic disks and retinal vessels were drawn (Fernard and Chase, 1971) on a tangent plexiglas screen and the area of central vision was estimated according to the criteria of Bishop et al. (1962). Artificial pupils of $4 \mathrm{~mm}$ diameter were put in front of the cycs. A concentric stimulating electrode was inserted into the lateral geniculate body (A6/L9.5). The position of the stimulating electrode was adjusted so that evoked field potentials could be clearly recorded with a spot of light shone onto the area of central vision. Classical criteria (Bullier and Henry, 1979) were used to identify "first-order" neurons, namely cells that could be driven monosynaptically from LGN, and those of a higher ordinal position.

Recording. Postsynaptic membrane potentials were recorded from neurons in area 17 using a patch electrode (pulled from hard borosilicate glass) with a tip diameter of $1-3 \mu \mathrm{m}$ and an impedance of 2-7 $\mathrm{M} \Omega$ after filling with the following solution (Edwards et al., 1989): $130 \mathrm{~mm} \mathrm{~K}$-gluconate, $5 \mathrm{~mm} \mathrm{NaCl}, 10 \mathrm{~mm}$ EGTA, 10 mм HEPES, 1 mм ATP, 1 mм $\mathrm{CaCl}_{2}, 2 \mathrm{mM} \mathrm{MgCl}, \mathrm{pH} 7.4$ with $\mathrm{KOH}$ (all drugs from Sigma Chemie GmbII, Deisenhofen). Access to the intracellular compartment of cells in or close to layer IV was achieved as per methods detailed elsewhere (Pei et al., 1991). The ocular dominance, optimal orientation and minimum discharge zone (Barlow et al., 1967) were determined from spike responses using a hand held torch both, whenever possible, before the establishment of the whole-cell mode as well as afterward. Later tests were restricted to the dominant eye. Cells were classified as simple, complex, or hypercomplex according to the criteria of Hubel and Wiesel (1962), Henry (1977), and Kato et al. (1978). For simple cells, the discharge fields could be divided into spatially separable ON and OFF zones, the response profiles of such zones peaked at a single point, and lengthening a slit stimulus at optimal orientation beyond the limits of the discharge zone did not abolish the response (no or weak "endinhibition"). For complex cells, responses evoked from the discharge zone were mixed ON and OFF, and maximum or close to maximum impulse rates could be evoked from an extent area of discharge zone. Complex cells had no or weak "end-inhibition." Cells with strong "endinhibition" were classified as hypercomplex, which may be of the simple or complex type. The data presented here are based on simple cells.

DC membrane potentials were amplified, filtered $(0-10 \mathrm{kHz})$, digitized (10-20 kHz) and finally fed into a data acquisition computer (VAX-3200) for further analysis. In order to avoid the distortion of spikes in the averaged curves, spikes were removed from each single sweep before the data were averaged. For that, a software filter was used, which first identified the location of a spike and then removed it from its starting point to its end, and finally linearly interpolated the continuous signal from the membrane potentials before and after the spike (Lankheet et al., 1989).

In addition to the intracellular recordings from cortical cells, the spike discharges of 56 LGN cells were recorded extracellularly under similar stimulation conditions. They served as a complementary study of the properties of the input fibers to cortical cells. These cells were classified into sustained $(X)$ and transient $(Y)$ cells (Cleland et al., 1971). Fourteen out of the 56 cells were ON sustained (X) cells, 9 OFF sustained (X), $11 \mathrm{ON}$ transient $(\mathrm{Y})$, and 17 were $\mathrm{OFF}$ transient $(\mathrm{Y})$ cells. Five cells were not classified. RF center sizes varied with a mean diameter of 1.65 $\pm 0.81^{\circ}$

Stimulation. Visual stimuli were presented on the tangent plexiglas screen, covered with a sheet of white paper, at a distance of $57 \mathrm{~cm}$ from the animal's eyes. A computer (PC-386; PEACOCK) controlled flashing slits or spots of different width and length that were generated with a back projector (PRADO). The unattenuated luminance was $30 \mathrm{~cd} / \mathrm{m}^{2}$. Background luminance was $0.5-1 \mathrm{~cd} / \mathrm{m}^{2}$. To analyze the spatial and temporal properties of excitatory and inhibitory potentials, the following stimulation routines were used. (1) For one-dimensional $R F$ plot, a light slit was flashed at different positions (usually 11) across the RF with positions separated by $0.3-1.0^{\circ}$. Tests were usually made in both optimal and nonoptimal orientations. (2) For two-dimensional $R F$ analysis$R F$ mapping-a small light spot (usually, $0.5^{\circ} \times 0.5^{\circ}$ ) was flashed over the RF in a matrix (usually $5 \times 5$ ) with a step size of $0.3-1.0^{\circ}$.

In order to eliminate or reduce interactions between adjacent regions in the RF, due to the stimulation sequence, stimulus presentations were quasi-randomly ordered; that is, the odd numbered $(1,3,5,7 \ldots)$ stimuli were presented first and then the even numbered $(2,4,6,8, \ldots)$ stimuli. Between subsequent stimuli there was an interval of 1.0-3.0 sec. For flashing stimuli, light-on duration was $0.5-1.5 \mathrm{sec}$ with an interval of 1.0-3.0 sec interposed between subsequent presentations.

\section{Results}

Receptive field analyses using flashing stationary stimuli were done on 20 simple cells. We would use the word "discharge field" to refer to the region from which spike discharges could 
Figure 1. Response analysis of a simple cell with scparate $O N$ and OFF discharge zones. An optimally oriented slit was flashed at different positions over the RF (compare scheme on the top right; slit was $5^{\circ} * 0.4^{\circ}$, orientation $140^{\circ}$, step size $0.5^{\circ}$; positions are indicated by numbers). Left column, Superimposed recordings of membrane potential during the first $200 \mathrm{msec}$ after stimulus was switched on. Two dashed lines mark the starting positions of early and late EPSP responses (arrows). The hatched arrow (position 4) points to a hyperpolarization in the response. Middle column, Averaged membrane potentials from five sweeps at low time resolution. Response amplitudes in the averaged curves appear to be smaller than in the single recordings because a bin width of $20 \mathrm{msec}$ was used for averaging. Numbers correspond to stimulus positions in the scheme. Right column, Superimposed recordings of membrane potential during the first $200 \mathrm{msec}$ after switching light off. Two dashed lines mark the starting positions of early and late EPSP responses to light off ( $a r-$ rows). Single histograms on the right, PSTHs of discharge responses of the cell, which could be evoked from three positions only.

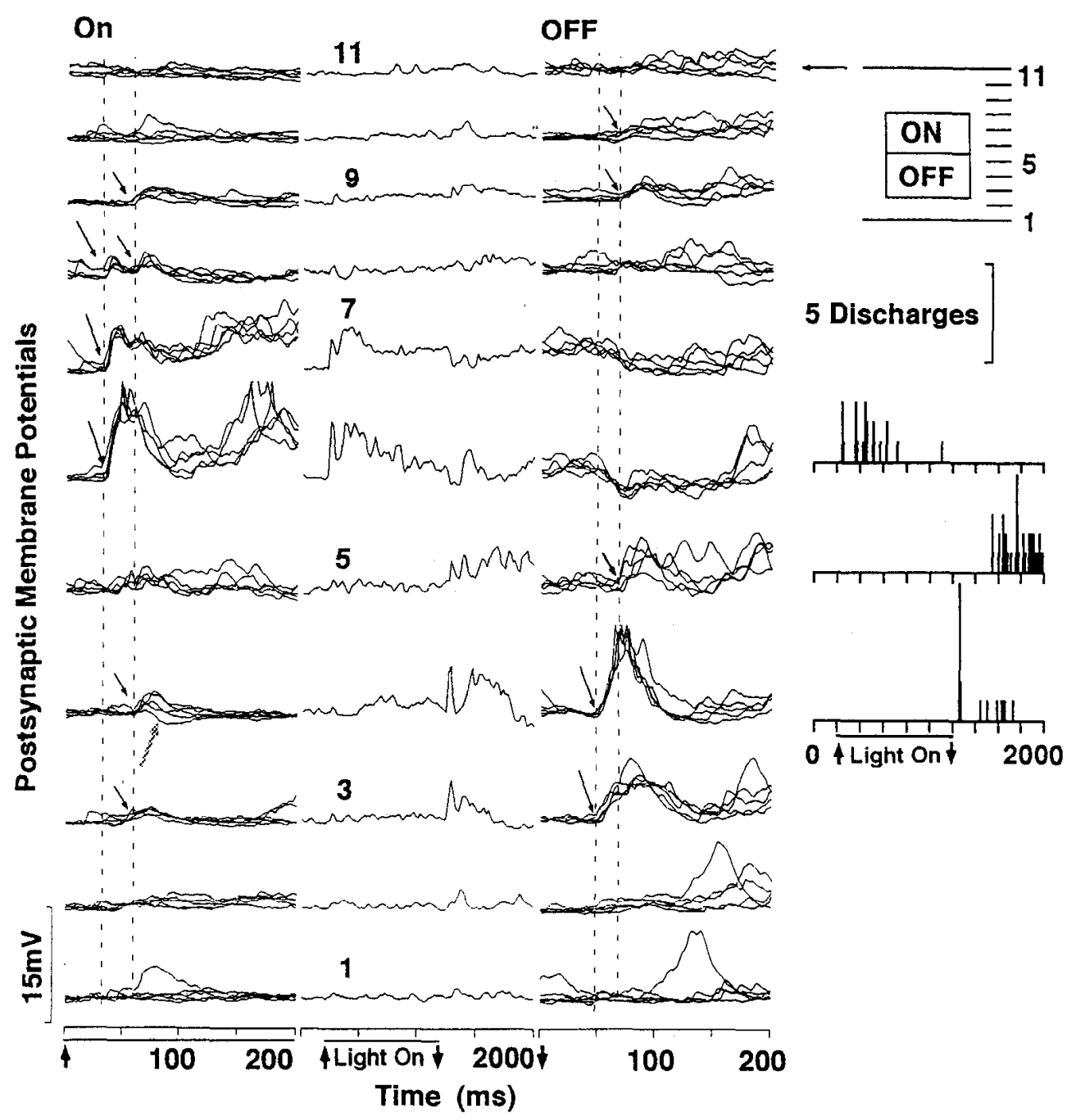

be evoked with a visual stimulus. "Excitatory input field" would be the region from which EPSPs could be evoked and "inhibitory field" from where IPSPs could be evoked. The forms of discharge fields of simple cells recorded intracellularly in this study were similar to that of the discharge fields recorded extracellularly in other studies (Camarda et al., 1985). They had either a single ON (three cells), a single OFF (three cells), or spatially separated $O N$ and OFF discharge zones (10 cells had two zones, four cells had three zones).

The EPSP responses evoked with a flashing stimulus could be divided into an early and a late component. The early component was synchronized to the stimulus onset with a relatively short latency. The main excitatory input field was always larger than the discharge field of a cell and usually had a more complicated structure, with the excitatory field having more subsections than the discharge field. Discharge zones represented only subsections of the excitatory input field where excitation exceeded the firing threshold of the cell. Excitatory and inhibitory input fields were also usually seen to overlap each other.

The structure of the RF's of cortical neurons were investigated both by flashing slits along the two axes of the field and by flashing spots over a two-dimensional $(5 \times 5)$ matrix. These results will be described separately.
One-dimensional RF measurement. The main purpose of these measurements was to estimate the elongation of the RF subregions. This was done by measuring the length and width of the input fields evoked in response to a bar flashed at different positions in the optimum and nonoptimum orientations. Figures 1 and 2 provide an example of the receptive field of the postsynaptic potentials of a simple cell. This RF is the area from which PSPs (either EPSPs, IPSPs, or both) could be evoked by visual stimulation. Responses in the optimum orientation are shown in Figure 1 and those in the nonoptimum orientation in Figure 2. The cell had two spike discharge zones, as shown schematically in the upper right corner. Flashing an optimally oriented slit at different positions over an area that covered the RF (as indicated in the upper right corner of Fig. 1), ON discharges (spikes evoked by light on) were obtained at position 6 with a latency of about $50 \mathrm{msec}$, OFF discharges (spikes evoked by light off) at position 4 with a latency of about $65 \mathrm{msec}$ and at position 5 with a longer latency of around $300 \mathrm{msec}$ (right column of Fig. 1). Nonoptimally oriented stimuli (Fig. 2) evoked no spike response from this cell.

EPSP responses, however, could be evoked by slits both in optimal and nonoptimal orientations. When a slit was flashed at the optimal orientation, EPSP responses to light on were 


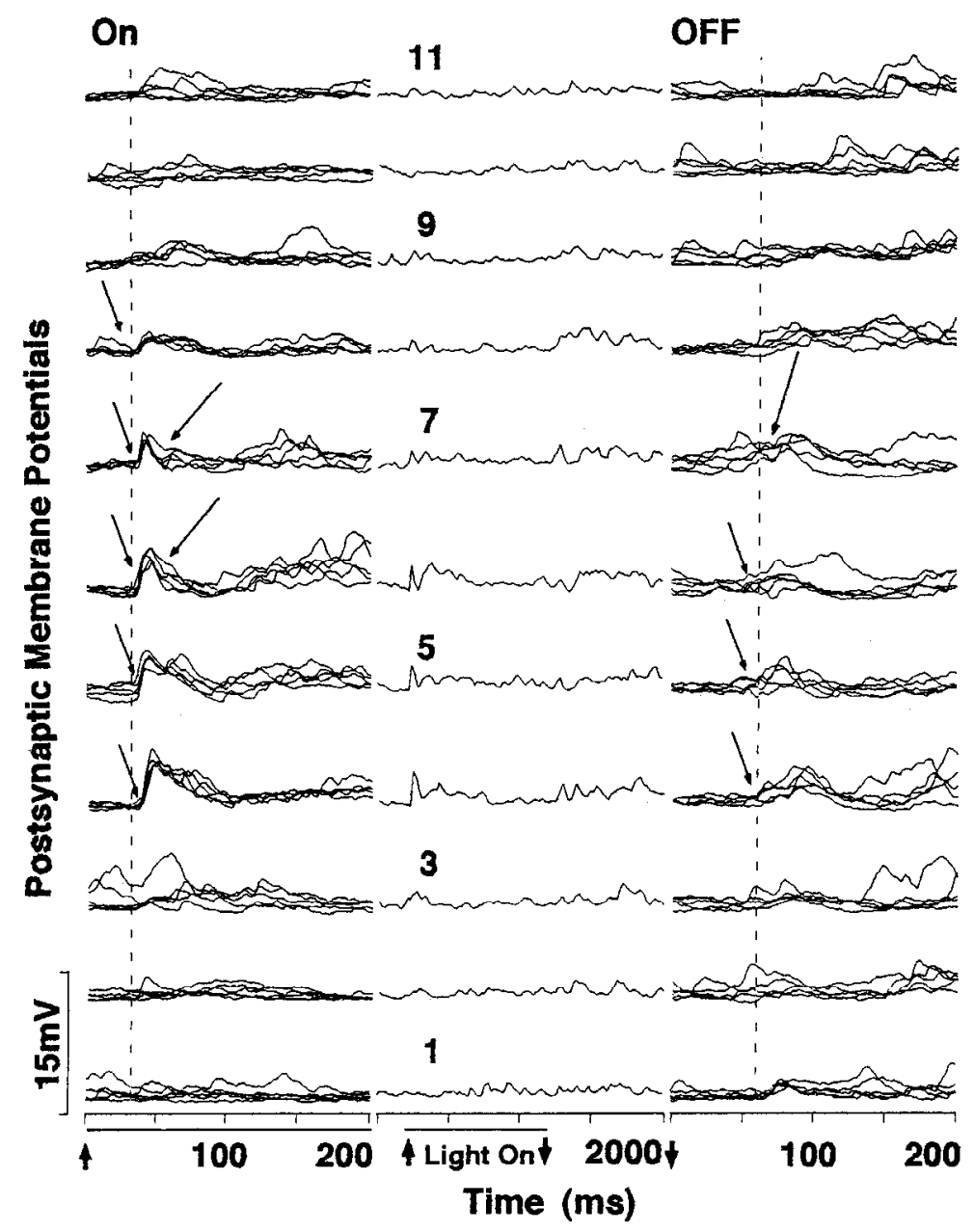

Figure 2. Recordings from the same cell as in Figure 1, but now with a nonoptimally oriented slit flashed at different positions over the RF (scheme on the top right; orientation, $50^{\circ}$, that is, orthogonal to the orientation in Fig. 1; slit and step sizes were the same as in Fig. 1). Notice that the cell did not fire during stimulation at nonoptimal orientation. The dashed lines in the first and third columns mark the starting positions of the early EPSP responses to light on and to light off (arrows on the left). Arrows on the right side of the lines indicate possible events of inhibition. The decay of EPSPs at positions 6 and 7 in the left column was faster than that at positions 4 and 8 . observed at positions 3-9 and to light off at positions 2-5 and 8-10. An early EPSP response component to light on was evoked only at positions 6-8. EPSP responses occurred with a latency of about $35 \mathrm{msec}$ after stimulus onset (Figs. 1, 2, long arrows on the left) and were well synchronized. The whole ON EPSP field, however, reached from position 3 to 9 and hence was more than twice as broad as the ON discharge zone. The early EPSP response was appreciable also in the nonoptimal orientation (Fig. 2, arrows to the left of the dashed line in the left column). The amplitudes of ON EPSP responses to stimuli at the nonoptimal orientation were around $55 \%$ of those to stimuli at the optimal orientation. These EPSP responses were also synchronized to stimulus onset and had the same latency as those to slits in the optimal orientation (compare Figs. 1, 2, first dashed lines in left columns). The excitatory input field of the early $\mathrm{ON}$ EPSP response was estimated to be about $1.5^{\circ}$ wide and $2.5^{\circ}$ long, that is, to be slightly elongated along the axis of optimal orientation with a ratio of 1.7 .

Synchronized early EPSP responses to light off were evoked by an optimally oriented slit (Fig. 1) at positions 3 and 4 (arrows to the left of the dashed line, third column) with a latency of $47 \mathrm{msec}$. Such responses were much smaller with a nonoptimally oriented slit (Fig. 2). The excitatory input field of early OFF EPSP responses was about $1^{\circ}$ wide and $1.5^{\circ} \mathrm{long}$ (ratio of 1.5 ), elongated along the axis of optimal orientation and parallel to the ON excitatory input field. The OFF EPSP response field was also broader than the discharge zone.
It is most likely that the early components of the PSPs wc have described so far reflect less of the corticocortical inputs than do the later components. So we studied the late components of the PSPs as well. The spatial structure of the late component of PSP responses was different from the early component. It depended also on the orientation and the position of the stimulus. With an optimally oriented slit (Fig. 1), a late ON EPSP response, which appeared around $20 \mathrm{msec}$ after the appearance of the early component as indicated by the second dashed lines in the first and third columns in Figure 1 , could be evoked at positions 6 and 7 , though at position 7 there were no spike discharge at all (Fig. 1, PSTHs on the right). In the nonoptimal orientation (Fig. 2), the late ON EPSP response was pronounced only at position 6 and was shorter than the late ON EPSP response in the optimal orientation. The membrane potential decreased to resting level in $400 \mathrm{msec}$ after light on in the nonoptimal orientation, whereas membrane depolarization lasted more than $800 \mathrm{msec}$ in the optimal orientation.

Similar observations were made with the late OFF components. Switching off an optimally oriented stimulus produced late depolarizations at positions 3-5. The nonoptimally oriented stimuli evoked little late depolarization. The late depolarization to light off of an optimally oriented slit at position 5 was particularly intcresting, for there was no short-latency OFF EPSP response. The late OFF PSP responses may be the result of OFF excitation together with the effect of termination of $O N$ inhibition. 
Figure 3. Two-dimensional field profile $(A)$ of the early PSP responses to light on in a first-order simple cell plotted with a small spot of light $\left(0.5^{\circ}\right.$. $\left.0.5^{\circ}\right)$. The scheme indicates the positions of the stimuli relatively to the RF. The plot covers an area of $5^{\circ} * 5^{\circ}$, with $X$ and $Y$ representing two spatial axes. The $\mathrm{z}$-axis gives amplitude of PSP responses, measured as the voltage difference between two recording times, one before, one at maximum response (dashed lines in $B-D$ ). $B-D$, Superimposed records of the membrane potential during the first $200 \mathrm{msec}$ after stimulation at positions $b, c$, and $d$ (in $A$ ), respectively. The first dashed line was the starting point of the membrane depolarization after onset of visual stimulation. The second dashed line was 20 msec later (right dashed line), when the excitation was close to maximum. To get the plot in $A$, the amplitude difference of membrane potentials between these two positions was calculated for all stimulus presentations. The shaded are $a$ around position $\mathrm{c}$ was the subfield with an inhibitory response to light on, corresponding to the OFF area in the scheme. $B$ shows the largest excitatory, and $C$, the largest inhibitory responses obtained. $D$, No response evoked; the membrane potential was at the resting level $(-47 \mathrm{mV}) . E$, Two-dimensional response profile of another simple cell, where the presentations were in a matrix of $5 \times 5$, instead of $11 \times 11$ as in $A$.
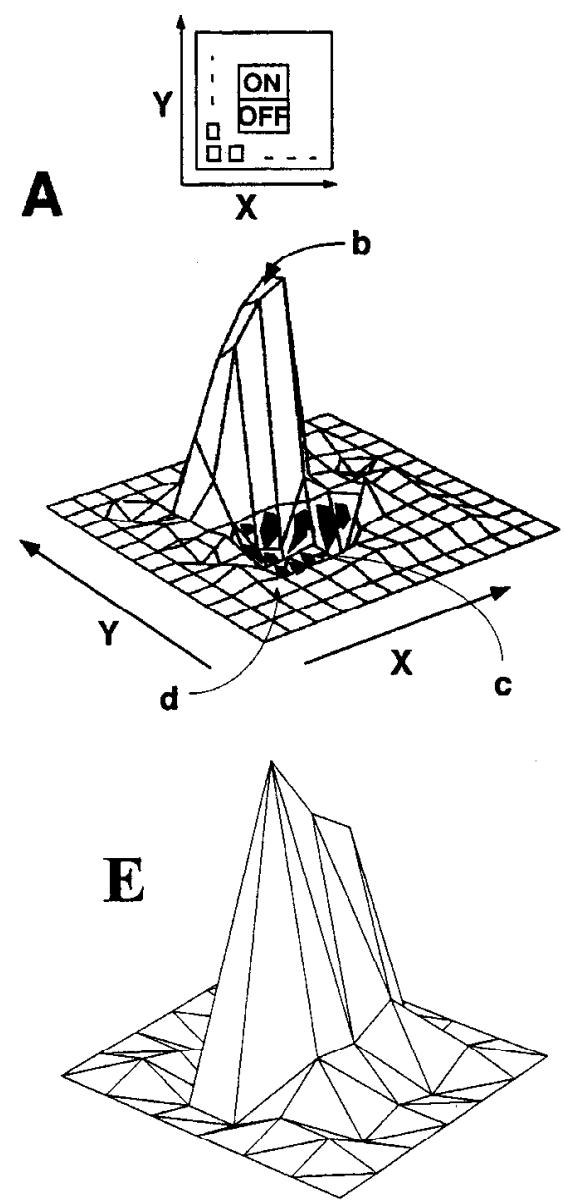

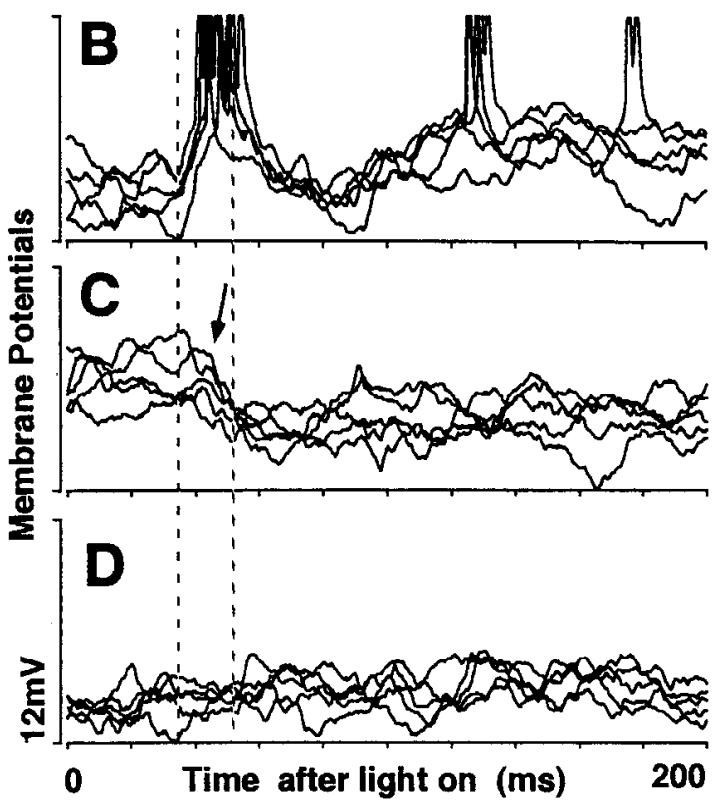

0 Time after light on (ms)
Outside the main excitalory fields, weak ON and OFF excitation with longer latencies (about $57 \mathrm{msec}$ for ON EPSPs and $75 \mathrm{msec}$ for OFF EPSPs) could be evoked with optimally oriented stimuli as indicated by the short arrows between the dashed lines in Figure 1 (left column, positions 3 and 4; third column, positions 9 and 10). Their occurrence depended on stimulus orientation for they could not be observed with a nonoptimally oriented slit or with a small spot. Late excitatory potentials could also be evoked from the main excitatory fields (e.g., Fig. 1, left column, position 7 , and third column, position 5, arrow). Hcrc, however, they interacted with other EPSPs and IPSPs and could not be isolated. A small light spot flashed over the RF (not shown) evoked both early ON and early OFF EPSP responses, which had slightly longer latencies than for a long slit $(38 \mathrm{msec}$ for ON EPSP responses driven from the ON field and $57 \mathrm{msec}$ for OFF EPSP responses driven from the OFF field). The elongation of the RF measured with a small light spot was similar to the elongation of the RF measured with a slit.

In this cell, the ON and OFF discharge fields were well separated, as were the $\mathrm{ON}$ and OFF excitatory fields of the early PSP components. Similar responses were obtained from four other simple cells, which also had more than one, but clearly separate, discharge fields. For the remaining cells, excitatory subfields partially overlapped.

Two-dimensional RF measurement. Two-dimensional response profiles of early PSPs were done on six cells by flashing a small spot of light on a $5 \times 5$ matrix as explained in Materials and Methods. The response profiles of each (ON or OFF) subfield was generally comparable to the sensitivity profiles of single LGN cells, with the elongation ratio of cortical PSP fields being only marginally larger than those of LGN cells. There was no noticeable center-surround structure in early PSP response fields. Since inhibition is not directly visible in spike discharges, the center/surround structure of an LGN cell would not be reflected in its output or in the cortical PSPs, unless the LGN cell has high spontaneous activity. Figure $3 A$ shows the profile of an early PSP response field of a simple cell. EPSPs (Fig. $3 B$ ) could be evoked from the ON subfield by a light spot with a latency of $33 \mathrm{~ms}$. The ON field was elliptical, with an elongation ratio of about 1.5. Outside this field, no early EPSPs were recorded (Fig. 3D), indicating that the cell received well centered excitatory projections from the LGN. The inhibitory response field was adjacent to the excitatory field, with a continuous transition between them. IPSPs identified as fast downward deflections of the membrane potential (arrow in Fig. $3 C$ ) appeared at $36 \mathrm{msec}$ after light on. The hyperpolarization of the membrane lasted almost as long as the light was on. The field of inhibitory responses in this cell was asymmetrical. Switching the light off in the ON field did not evoke membrane hyperpolarization (not shown).

Switching the light off depolarized the membrane with a latency of $45 \mathrm{msec}$ (not shown), which was $12 \mathrm{msec}$ longer than that of ON EPSP responses in an area (the OFF subfield) slightly larger than the ON inhibitory field. The OFF excitatory field 


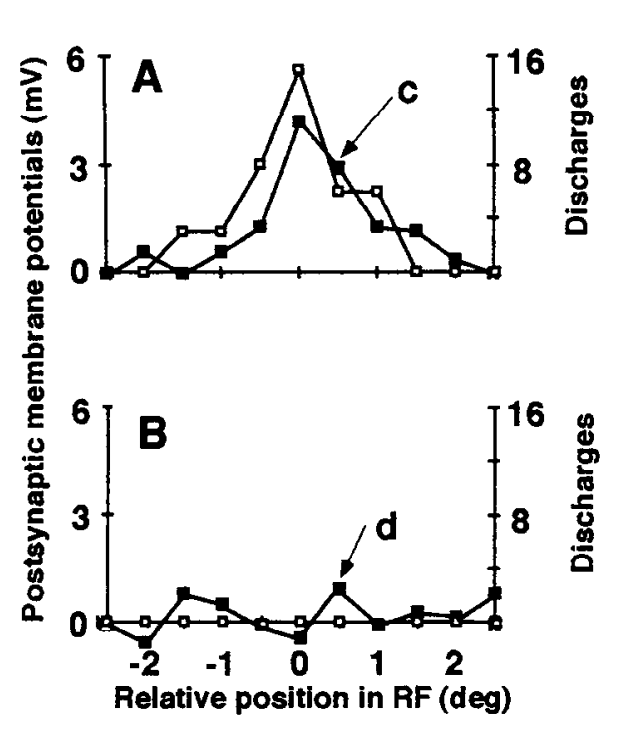

Figure 4. One-dimensional field plots of a sccond-order simple cell obtained with a light slit $\left(5^{\circ} \cdot 0.3^{\circ}\right)$ at optimal $(A)$ or nonoptimal $(B)$ orientation. The curves with solid symbols give the deflection of membrane potential as measured between the dashed lines in $C$ and $D$. The curves with open symbols are from spike discharges. $C$ and $D$ show averaged records $(n=5)$ of membrane potentials to stimuli at positions $c$ and $d$ in $A$ and $B$, respectively. was also elongated along the optimal orientation axis, with a ratio of 1.3 .

Figure $3 E$ shows another example of a PSP response field of a simple cell. The inhibition evoked in this cell was weaker than that in Figure $3 A$ and no inhibitory input field could be measured with a small spot stimulus.

$R F$ measurement in second-order cells. For second-order simple cells, the early PSP responses were usually already highly selective to the orientation of the stimulus, both for simple cells with several discharge zones and for those with only one discharge zone. Figure 4 shows a second-order simple cell with one ON discharge zone. The RF of postsynaptic potentials of this cell had three subsections, an ON subfield from which PSPs and ON discharges could be evoked and two OFF subfields from which PSPs could be evoked, but not spike discharges. The two OFF subfields could be distinguished only by intracellular analysis. Since the EPSPs were highly sensitive to orientation, large EPSP responses could be evoked only by an optimally oriented slit (Fig. $4 A, C$ ). EPSP responses were very small in the nonoptimal orientation (Fig. $4 B, D$ ). Therefore, it was not possible to measure the elongation of the RF with the method used here. In the nonoptimal orientation no discharges were elicited from the cell. Further, no short-latency and synchronized OFF EPSP responses could be evoked from the OFF subficlds. The OFF EPSP responses (not shown) observed at both sides of the $O N$ subfield had a latency of 80-100 msec and lower amplitudes than the ON EPSP responses. They were spatially symmetrical to the central ON excitatory field.

Comparison with LGN RFs. If there is significant excitatory convergence of geniculate inputs onto simple cells as suggested by Hubel and Wiesel (1962), the length of EPSP input fields of simple cells should be many times the diameter (or length, for biased cells) of LGN spike response fields. So we have compared the simple cell excitatory input field lengths to those of LGN spike response fields at approximately the same visual eccentricity. In Figure 5, the amplitudes of the early responses of the cell (shown in Figs. 1,2) to stimuli flashed on or off in optimal (Fig. $5 A$ ) and nonoptimal (Fig. $5 B$ ) orientations are plotted. Amplitudes were measured as the difference between the membrane potentials before the response and at maximal depolarization or hyperpolarization. There was a clear separation of the
$\mathrm{ON}$ and OFF excitatory fields (solid and dashed lines in Fig. $5 A$ ). From the left to right in Figure $5 A$ (corresponding to positions 1 through 11 in Fig. 1), responses to light off increased to its maximum and then decreased quickly to zero. From right to left the same happened for responses to light on. ON and OFF responses both fell to zero at the same stimulus position $\left(-0.5^{\circ}\right.$ in Fig. $\left.5 A\right)$. The early peak of spike discharges occurred at the pcak positions of carly excitatory responsc ficlds. In comparison to the profiles of the ON and OFF subfields in this cell, RF profiles of LGN cells [compare ON sustained (X) cell in $\mathrm{C}$ and an OFF sustained (X) cell in Fig. 5D] were typically somewhat smaller in size at similar retinal eccentricity. However, the widths of cortical PSP fields were only rarely more than twice the field widths of LGN spike responses. With a limited elongation ratio, this means that excitatory convergence along the length axis of the receptive field is also limited.

In the LGN cells, the early transient responses were more than twice the late sustained responses. However, the RF profiles of the late sustained components of both cells (Fig. $5 C, D$, open symbols) were similar to those of the early transient components (solid symbols). Only firing frequency was decreased. By contrast, in the cortical cell the late component of excitation was not much smaller than the early component (position 6 in Fig. 1) or was even larger (position 7 in Fig. 1), but was clearly orientation selective. This indicates that, in addition to the excitatory inputs from the LGN, a large amount of excitatory inputs might come from other cortical cells.

In summary, for the majority of first-order cells (14 cells), the excitatory input fields were slightly elongated along the optimal orientation axis with a mean ratio of axes of about $1.7 \pm 0.8$ and a range of $1-4$. In 11 cells, both an optimally oriented and a nonoptimally oriented stimulus evoked early excitatory responses and the amplitude in the nonoptimal orientation was generally one-third to two-thirds of that in the optimal orientation. In the remaining six cells the excitatory responses in the nonoptimal orientation were much weaker. Three of these cells had long latencies to electrical stimulation in the LGN, only one received a short-latency $L G N$ drive, indicating a definitive monosynaptic input. The late components of PSP responses were usually smaller in the nonoptimal than in the optimal orientation. Also, the late membrane hyperpolarization evoked 
Figure 5. RF profiles $(A, B)$ of early components of PSP responses (same cell as in Figs. 1,2) and RF profiles of an ON center $(C)$ and an OFF center $(D)$ LGN cell. The abscissae represent the relative positions of stimuli in the RF (slit $5^{\circ} \cdot 0.4^{\circ}$, step size $0.5^{\circ}$ ). $A$, RF profile of early components of PSP responses to stimuli at optimal orientation. The solid line represents the ON responses, the dashed line the OFF responses, negative values indicate membrane hyperpolarization. $B$, Same analysis with stimuli in nonoptimal orientation. The solid line gives the ON responses, the dashed line the OFF responses to stimuli at various positions over the RF. No discharges were obtained with stimuli at this orientation. $C, \mathrm{RF}$ profile of an ON center LGN cell. Solid symbols represent the transient response component and open symbols the sustained component. Stimulus presentation (light on) as indicated below the histogram. $D$, RF profile of an OFF center LGN cell (symbols as in $C$ ).
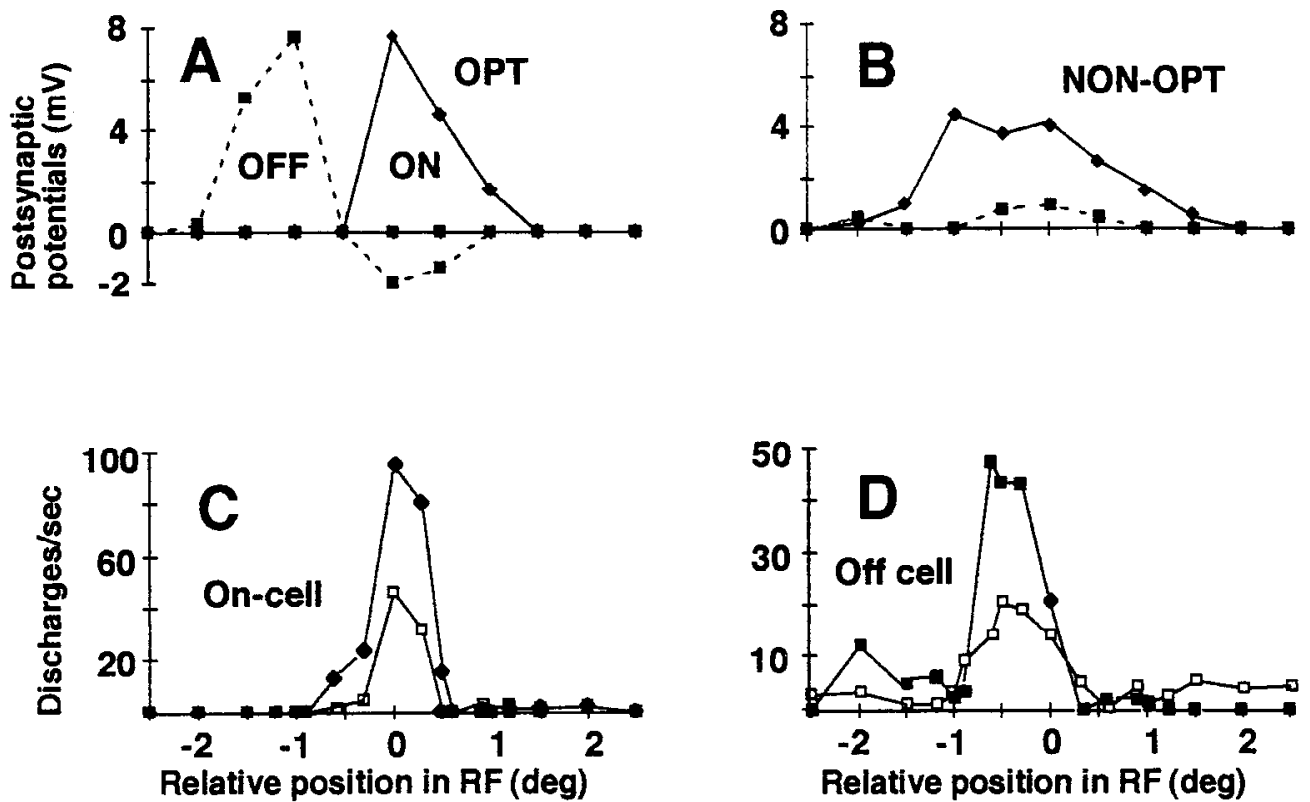

from the inhibitory field was smaller in the nonoptimal than in the optimal orientation.

Orientation preference of PSP responses. Since the structure of the EPSPs of striate cortical simple cells did not reveal the degree of elongation along the axis of optimum orientation that would explain their orientation selectivity, we explored further the possibility of the involvement of inhibitory mechanisms in orientation selectivity as well as the role of temporal factors related to excitatory and inhibitory inputs. From PSP responses elicited with long bars of different orientations flashed on the center of the dominant discharge zone of simple cells, we were able to measure for some cells the dependence on orientations of EPSPs and IPSPs at different times after the onset of stimuli.

Figure 6 shows averaged PSP responses of four different cells at the optimum and nonoptimum orientations in the left and middle columns and superimposed individual traces at the nonoptimum orientation on the right. Only in a minority $(10 \%)$ of first-order cells was there no evidence of inhibition in the nonoptimum orientation and the EPSPs were tuned to the optimum orientation. This is exemplified by the cell shown in Figure $6 \mathrm{~A}$.

However, in most cells, stimuli of nonoptimum orientation do evoke inhibition. This is often quite clear as in the cells shown in Figure 6, $C$ and $D$. In Figure $6 B$, EPSPs are present in both orientations (thin lines), but they seem to be gradually suppressed by the developing inhibition in the nonoptimum orientation. When the IPSPs were suppressed by hyperpolarizing the cell (thick lines in Fig. $6 B$ ), the EPSP amplitudes in the optimum and nonoptimum orientations were equal. In Figure $6 D$, EPSPs and IPSPs are tuned to orthogonal orientations and no large IPSPs are visible in the optimum orientation and no EPSPs in the nonoptimum. The small hyperpolarization seen in the optimum orientation can easily be due to after potentials. Figure $6 C$ shows a cell where it is difficult to discern in the averaged PSPs an IPSP in the nonoptimum orientation that is reliably above the noise level. However, inspection of the individual traces (bottom) clearly shows the sharp IPSPs that arise with a latency of around $5 \mathrm{msec}$ after the onset of excitation.
Since there is some jitter in the onset of EPSPs and IPSPs, the averaged trace in the middle does not show the IPSP. Thus, even in cells where averaged traces show no IPSPs in the nonoptimum orientation, there can in fact be significant IPSPs that contribute to orientation selectivity.

IPSPs evoked by stimuli of nonoptimal orientations usually had bit longer latencies than the early EPSPs. In Figure 7, the PSP responses to flashing bars of different orientations are shown on the left (Fig. $7 A$ ) for the same cell that was described in Figures 1 and 2. EPSPs are visible in all orientations, even though they attain higher amplitudes in the optimum orientation. The individual traces show little jitter and when the averaged responses at different orientations are superimposed (Fig. $7 B$ ), it can be seen that the slopes and amplitudes of the initial phase of the EPSPs are very similar at all orientations. However, after a period as short as $10 \mathrm{msec}$, the EPSPs around the nonoptimum orientation appear to get cut off by a rapidly decaying component, that can be best interpreted as inhibition. The unusually fast decay of the EPSPs in the nonoptimal orientations contrasts with the plateau and slow decay of purely excitatory events, as seen for the same cell in positions 1 and 9 in the left column of Figure 1. Such fast decay can be interpreted as inhibition following initial excitation with a small delay. It can be seen from the averaged responses in Figure $7 B$ that the EPSPs begin to show differences in amplitude between orientations after the first 5 or 6 msec. With time, the differences become marked. The orientation luning curve measured from the amplitude of EPSPs at $5.7 \mathrm{msec}$ after the onset of the excitatory responses (thick line in Fig. $7 \mathrm{C}$ ) is very broadly tuned to orientation. The tuning curve measured $6 \mathrm{msec}$ later (i.e., $13 \mathrm{msec}$ after response onset; thin line in Fig. $7 \mathrm{C}$ ) is more sharply tuned to orientation. This was due both to an increase in amplitude around the optimum orientation and a decrease around the nonoptimum. Finally, with further passage of time, the orientation tuning seen with spike discharges (dashed line in Fig. $7 \mathrm{C}$ ) is much sharper. The orientation tuning curve of the early EPSPs (thick line) is approximately what one would expect from the 

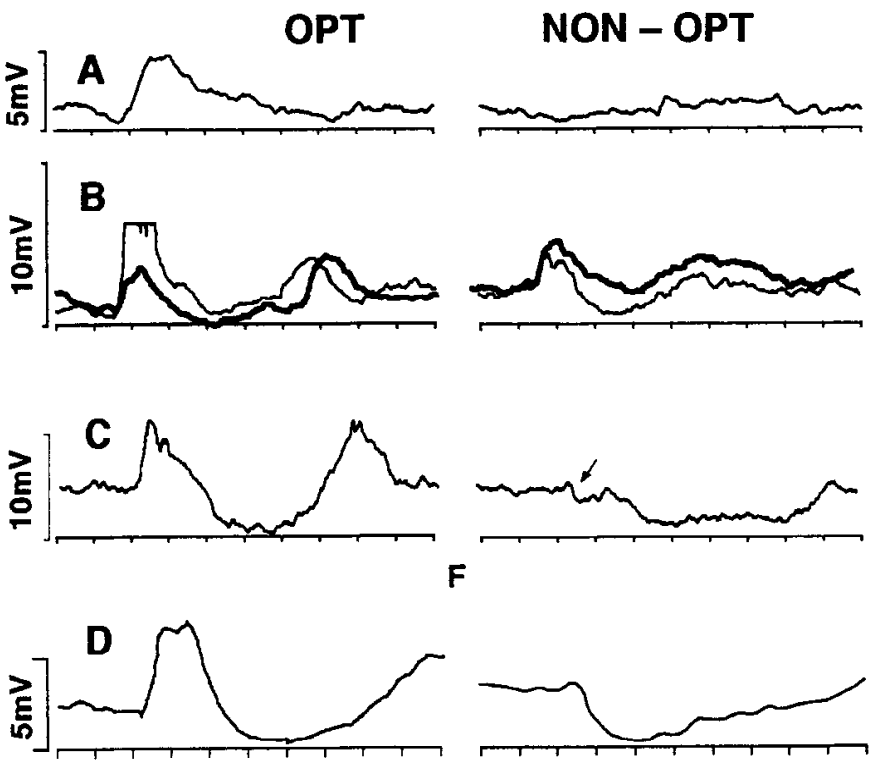

0

100

200

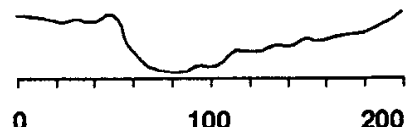

Time after light on (ms)
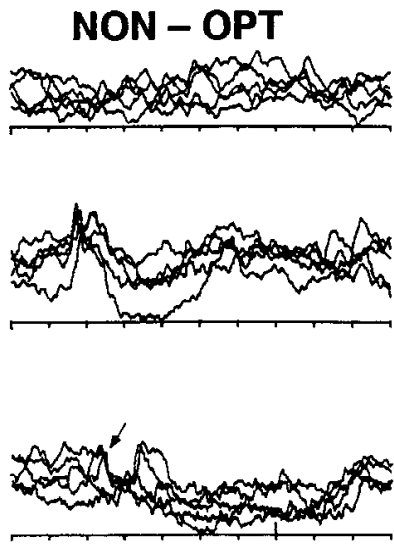

Figure 6. PSP responses of four different cells $(A-D$, thin lines) to a long bar flashed at the optimum (left) and nonoptimum (middle and right) orientations. The traces on the left for the optimally oriented bar are averaged re-

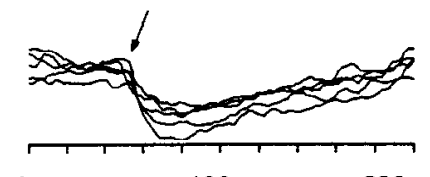
sponses to five prescntations. For the nonoptimally oriented stimulus, five individual traces are shown on the right and their averaged trace is displayed in the middle. The thick lines in $B$ were PSP responses with hyperpolarizing current. degree of elongation (ratio of 1.7) of the ON discharge zone, but within the next few milliseconds it is markedly sharpened, presumably due to inhibition.

In 11 cells, we were able to obtain separate orientation tuning curves for the primary excitatory and inhibitory PSPs. Figure 8 plots the optimum orientation of IPSPs against that of EPSPs for these cells. They differ by $45-90^{\circ}$ for all cells in this sample. However, this should not be taken as unequivocal evidence for cross-orientation inhibition as the mechanism of orientation selectivity for these cells. Without inactivation of excitation, say by neuropharmacological methods, it would not be possible to find out the true orientation tuning of IPSPs. Thus, it cannot be excluded that the optimum orientation for IPSPs may in fact be somewhat closer to that of the spike discharges than that indicated by the figures.

\section{Discussion}

First-order cells in the striate cortex, whether of the simple or the complex type, are subject to a number of synaptic inputs: an excitatory input from the dLGN via one or more afferents and both excitatory and inhibitory inputs from other cortical neurons. Our experiments have sought to identify the excitatory and inhibitory inputs that contribute to the receptive field structure and orientation selectivity. Whole-cell recordings using patch-clamp electrodes (Pei et al., 1991) enabled us to record intracellular potentials over periods long enough to analyze response properties and receptive field profiles in detail that was not possible with earlier methods using sharp electrodes (Creutzfeldt et al., 1974; Ferster, 1986). Our use of Hashing stimuli in addition to moving stimuli is a powerful tool in analyzing receptive field structures. Another recent study using whole-cell recordings (Ferster and Jagadeesh, 1992) employed only moving stimuli, which involve extensive spatiotemporal interactions and can confound any attempt at delineating receptive fields precisely.

Even though the PSP responses we obtained exhibited separate or overlapping $\mathrm{ON}$ and OFF regions just like the spike responses in extracellular recordings, the elongation (length:width) ratios of the excitatory response regions were very much lower. We obtained an average elongation ratio of 1.7 , whereas extra-

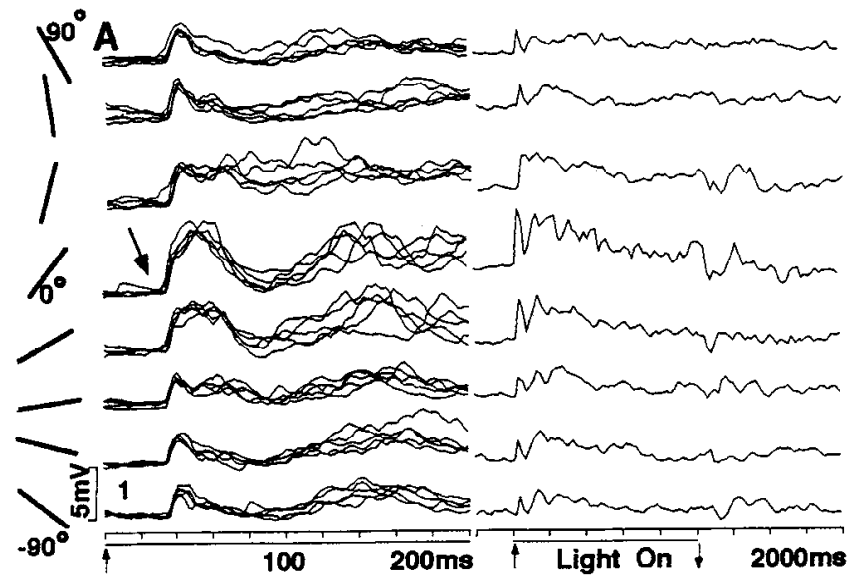

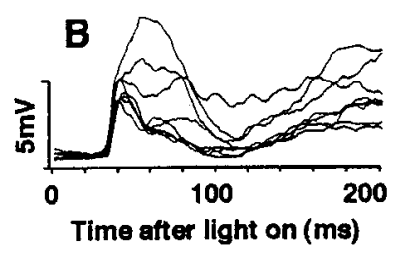

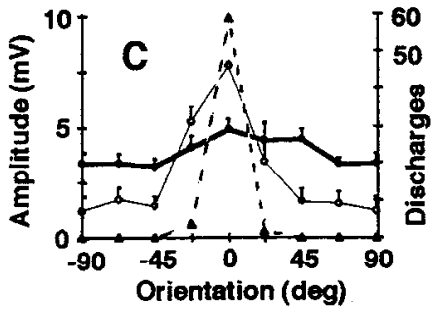

Figure 7. A, PSP responses to bars flashed at different orientations, centered on the ON discharge region. The time axis is shown at a fast (left) and a slow (right) scale. The different orientations are shown in the left margin. $B$, Superimposed averaged PSPs at the eight different orientations. $C$, Orientation tuning of the EPSP amplitude plotted at $5.7 \mathrm{msec}$ (thick line) and 13 msec (thin line) after the start of the EPSPs, and of spike discharges (dashed line). 


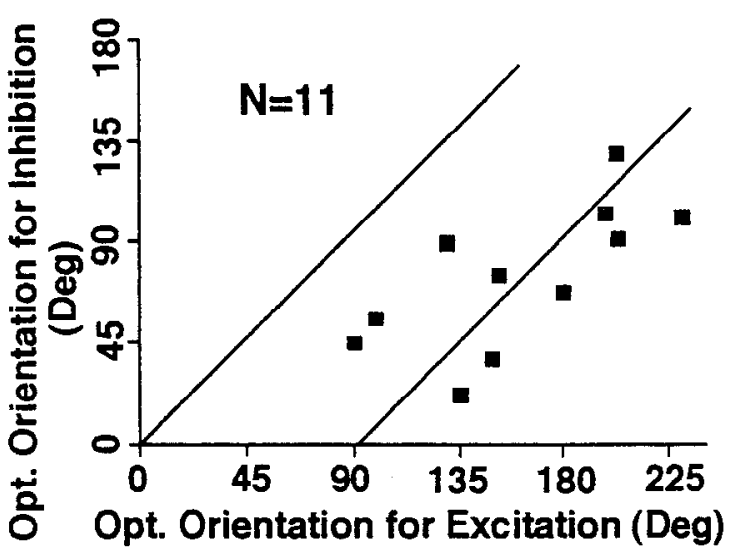

Figure 8. Optimum orientation of IPSPs plotted against optimum orientation of EPSPs for 11 cells, where orientation tuning of both excitatory and inhibitory PSPs could be calculated. The slope on the left would represent cells whose EPSPs and IPSPs were tuned to the same orientation, and the slope on the right, cells in which the optimum orientations of EPSPs and IPSPs differed by $90^{\circ}$.

cellular recordings in earlier studies had found much higher ratios. In one study (Jones and Palmer, 1987), the ratios ranged from 1.7 to 13 and in another study (Kato et al., 1978), the mean was around 8 . It should be mentioned here that in these studies the use of length summation curves to determine the RF length is likely to have led to some overestimation of the length:width ratio (Henry et al., 1978).

There are however many reasons for this apparent discrepancy between PSP and spike responses. First, the receptive fields of early EPSP responses represent all the primary excitatory inputs to the cell, whereas spike discharges represent the final outcome after excitation and inhibition arriving at the cell have had their postsynaptic effects, with inhibition often sharpening the response. Second, the opponent inhibition arising from the antagonistic flanks in a simple ccll would affect the width of the receptive field, but not the length. Third, there is also a firing threshold, which needs to be reached by the depolarization before spikes can be initiated. Fourth, the spatial summation seen in spike discharges along the length of the receptive field does not necessarily reflect the contribution of excitation from geniculate afferents to the particular striate cell as originally proposed (Hubel and Wiesel, 1962). There are two other possibilities. One is intracortical excitation arising from other cells tuned to similar orientation and mediated through the long-range horizontal connections (Ts'o et al., 1986; Gilbert and Wiesel, 1985) or through a local circuitry (Martin et al., 1991). The second possibility is disinhibition stemming from an inhibitory input that itself has strong end-inhibition in the long axis of the receptive field (Vidyasagar, 1987, 1989). In such a case, the excitatory PSP zone may be quite discrete, but the inhibition would be maximum for a small bar, and would diminish with increasing length and lead to length summation. Finally, there can also be nonlinearities in the synaptic input due to voltagemediated channels (such as NMDA or noninactivating sodium channels), which would greatly amplify any excitation that manages to overcome the inhibition (Tsumoto et al., 1979; Fox et al., 1989; Miller et al., 1989; Hirsch and Gilbert, 1991; Volgushev et al., 1992). Similar "acceleration" or "expansive" behavior of cortical cell responses after an initial preference for a particular stimulus dimension has also been suggested by others (Albrecht and Geisler, 1991; Douglas and Martin, 1991).

The degree of elongation we have seen is not much more than the elongation one often sees in geniculate cells (Vidyasagar and Urbas, 1982; Soodak et al., 1986; Shou and Leventhal, 1989) and certainly much less than what one would expect if excitatory convergence of geniculate afferents (Hubel and Wiesel, 1962) were to provide the elongated receptive field. Thus the excitatory input may arise from only one or a small number of geniculate fields. This implies that the thalamocortical excitatory input a typical cortical neuron receives is from a small number of geniculate receptive fields (or even a single field), forming at best a mildly elongated "cloud" rather than from a number of LGN fields forming a long row. This is not inconsistent (Vidyasagar, 1987) with the cross-correlation studies of Tanaka (1983), which suggest a geniculocortical convergence of about 10 LGN cells onto a cortical cell and the morphological studies of Freund et al. (1985) suggesting a convergence ratio of at least 12 . Since a single retinal cell provides the excitatory input to about 10 geniculate cells when averaged for both $\mathrm{X}$ - and $\mathrm{Y}$-type LGN cells (Friedlander et al., 1981), a thalamocortical convergence of 10 to 1 can be consistent with only slightly elongated cortical excitatory input fields. Our scheme would also be consistent with the cross-correlation studies between striate cells and retinal ganglion cells, which suggested that the excitatory input to a cortical cell arises from only one or a small number of retinal cells (Lee et al., 1977).

In most cases, the method we have used to calculate the elongation ratio was, as explained earlier, to flash a long bar at different positions in the optimal and nonoptimal orientations and measure the spatial extent over which EPSPs could be evoked. This ratio by itself does not help in calculating the orientation sensitivity of the EPSPs without knowing the twodimensional sensitivity profile over the receptive field. However, our direct measurements of the amplitudes of the EPSPs in the optimal and its orthogonal orientations can throw light on the orientation sensitivity of the excitatory input. In some cells, the EPSP amplitudes in the two orientations were not very different, suggesting a significant role for intracortical inhibition in producing the final orientation selectivity of spike discharges. Further, in most cells, early components of the EPSPs were nearly equal in both optimal and nonoptimal orientations and had similar latencies and rising slopes. It is only with time that the difference between the optimal and nonoptimal orientations becomes apparent, with the EPSP in the optimum orientation continuing to rise and that in the nonoptimum orientation getting sharply cut off by inhibition. This is consistent with the finding that if inhibition is removed pharmacologically by blocking the $\mathrm{GABA}_{\mathrm{A}}$ receptors (Sillito et al., 1980) or by inactivation of the intracortical inhibitory inputs (Eysel et al., 1990), the orientation tuning of the spike responses became broader. The decrease of response in the nonoptimal orientation cannot be due to surround inhibition at the LGN level because this would be present in the optimal orientation as well.

In a few first-order cells, where some orientation selectivity is present from the beginning, there could be some genuine excitatory convergence (Hubel and Wiesel, 1962) or an afferent input that is already biassed for orientation (Vidyasagar and Urbas, 1982). Only in rare instances (2 of 20 cells) did we encounter among first-order cells, clear sharply tuned EPSPs from the very beginning.

The increasing EPSP amplitude in the optimum orientation 
can be partly due to intracortical excitatory connections. Such horizontal connections are known to arise from cells tuned to similar orientations from columns located up to 6-8 $\mathrm{mm}$ apart (Gilbert and Wiesel, 1985; Ts'o et al., 1986). These inputs are likely to augment the EPSPs mainly in the optimum orientation. Such orientation tuned intracortical inputs may continue to arise for a considerable amount of time and may account for the late EPSP responses being very orientation sensitive. From this and from any orientation bias in the primary excitatory input, it follows that the inhibition required to suppress the responses in the nonoptimum orientation will not be excessive. With less excitatory load in the nonoptimum orientation, it is possible to get away with less inhibition. This may explain the observation that IPSPs are not always very striking in the nonoptimum orientation (Creutzfeldt et al., 1974; Ferster, 1986). It also resolves the dilemma posed by Douglas and Martin (1991): on the one hand, linear hyperpolarizing inhibition can increase the synaptic current required to bring the cell to firing threshold only by about $50 \%$ because of the relatively small difference between membrane potential and the IPSP reversal potential; on the other hand, they have found little evidence for nonlinear, shunting inhibition. In our scheme, the excitatory load in the nonoptimum orientation that needs to be suppressed is less due to both the factors mentioned above. Once there is a bias toward one orientation established through excitatory input bias and inhibition, a winner-take-all mechanism mediated through longrange lateral connections and/or through a local microcircuitry (Martin et al., 1991) and/or through voltage-dependent channels (Volgushev et al., 1992) can ensure a high degree of orientation selectivity developing with time. The late EPSPs in our recordings are always well tuncd for orientation and there is little evidence of IPSPs appearing at these latencies. Part of the sharpening in the membrane potential response over time can occur before the threshold for spikes is reached, but a part, especially the facilitation in the optimum orientation, is likely to occur after the threshold is reached. In some studies, spike discharges measured at different latencies after the onset of a stimulus have shown increasing orientation selectivity (Shevelev and Sharaev, 1981; Best et al., 1989), even though other studies have disputed this (Celebrini et al., 1993).

Our studies using whole-cell recording techniques to elucidate the functional significance of excitatory and inhibitory inputs to striate cortical cells have led to an eclectic basis for orientation selectivity. The sharp tuning that these cells exhibit is likely to be due to a variety of mechanisms. Thus, not only the dynamic interaction of excitation and inhibition on single cortical cells plays a role, but both subcortical mechanisms as well as longrange intracortical connections and local voltage-sensitive channels determine the ultimate response selectivities.

\section{References}

Albrecht DG, Geisler WS (1991) Motion selectivity and the contrast response function of simple cells in the visual cortex. Vis Neurosci 7:531-546.

Barlow HB, Blackmore C, Pettigrew JD (1967) The neural mechanism of binocular depth discrimination. J Physiol (Lond) 193:327-342.

Berman NJ, Douglas RJ, Martin KAC (1989) The conductances associated with inhibitory postsynaptic potentials are larger in visual cortical neurons in vitro than in similar neurons in intact anaesthetized rats. J Physiol (Lond) 187:P107.

Berman NJ, Douglas RJ, Martin KAC, Whitteridge D (1991) Mechanism of inhibition in the cat visual cortex. J Physiol (Lond) 440: 697-721

Best J, Mallot H, Krueger K, Dinse HRO (1989) Dynamics of visual information processing in cortical systems. In: Neural networks: from models to applications (Personnaz L, Dreyfus G, eds), pp 107-116. Paris: IDSET.

Bishop PO, Kozak W, Levick WR, Vakkur GJ (1962) The Determination of the projection of the visual field on to the lateral geniculate nucleus in the cat. J Physiol (Lond) 163:503-539.

Bishop PO, Coombs JS, Henry GH (1973) Receptive fields of simple cells in the cat striate cortex. J Physiol (Lond) 231:31-60.

Blakemore C, Tobin EA (1972) Lateral inhibition between orientation detectors in the cat's visual cortex. Exp Brain Res 15:439-440.

Bonds AB (1989) Role of inhibition in the specification of orientation selectivity of cells in the cat striate cortex. Vis Neurosci 2:41-55.

Bullier J, Henry G (1979) Ordinal position of neurons in cat striate cortex. J Neurophysiol 42:1251-1263.

Camarda RM, Peterhans E, Bishop PO (1985) Spatial organization of subregions in receptive fields of simple cells in cat striate cortex as revealed by stationary flashing bars and moving edges. Exp Brain Res 60:136-150.

Celebrini S, Thorpe T, Trotter Y, Imbert M (1993) Dynamics of orientation coding in area V1 of the awake primate. Vis Neurosci 10: $811-825$.

Cleland BG, Dubin MW, Levick WR (1971) Sustained and transient neurons in the cat's retina and lateral geniculate nucleus. J Physiol (Lond) 217:473-496.

Creutzfeldt OD, Ito M (1968) Functional synaptic organization of primary cortex neurons in the cat. Exp Brain Res 6:324-352.

Creutzfeldt OD, Kuhnt U, Benevento LA (1974) An intracellular analysis of visual cortical neurons to moving stimuli: responses in a cooperative neuronal network. Exp Brain Res 21:251-274.

Creutzfeldt OD, Vidyasagar TR, Guedes R, Li CY (1988) Basic synaptic thalamo-cortical circuitry of the cortical network. Front Excitatory Amino Acid Res: 455-462.

Daniels JD, Norman JL, Pettigrew JD (1977) Biases for oriented moving bars in lateral geniculate nucleus neurons of normal and stripereared cats. Exp Brain Res 29:155-172.

Douglas RJ, Martin KAC (1991) A functional microcircuit for cat visual cortex. J Physiol (Lond) 440:735-769.

Douglas RJ, Martin KAC, Whitteridge D (1988) Selective responses of visual cortical cells do not depend on shunting inhibition. Nature 332:642-644.

Douglas RJ, Martin KAC, Whitteridge D (1991) An intracellular analysis of the visual responses of neurons in cat visual cortex. J Physiol (Lond) 440:659-696.

Dreifuss JJ, Kelly JS, Krnjevic K (1968) Cortical inhibition and $\gamma$-aminobutyric acid. Exp Brain Res 9:137-154.

Edwards FA, Konnerth A, Sakmann B, Takahashi T (1989) A thin slice preparation for patch clamp recordings from neurons of the mammalian central nervous system. Pfluegers Arch 414:600-612.

Eysel UT (1992) Lateral inhibitory interactions in areas 17 and 18 of the cat visual cortex. Prog Brain Res 90:407-422.

Eysel UT, Crook JM, Machemer HF (1990) GABA-induced remote inactivation reveals cross-orientation inhibition in the cat striate cortex. Exp Brain Res 80:626-630.

Fernard R, Chase R (1971) An improved method for plotting retinal landmarks and focusing the eyes. Vision Res 11:95-96.

Ferster D (1986) Orientation selectivity of synaptic potentials in neurons of cat primary visual cortex. I Neurosci 6:1284-1301.

Ferster D, Jagadeesh B (1992) EPSP-IPSP interactions in cat visual cortex studied with in vivo whole cell patch recording. J Neurosci 12: $1262-1274$.

Ferster D, Lindström S (1983) An intracellular analysis of geniculocortical connectivity in area 17 of the cat. J Physiol (Lond) 342:181215.

Fox K, Sato H, Daw N (1989) The location and function of NMDA receptors in cat and kitten visual cortex. J Neurosci 9:2443-2454.

Friedlander MJ, Lin C-S, Stanford LR, Sherman SM (1981) Morphology of functionally identified neurones in the lateral geniculate nucleus of the cat. J Neurophysiol 46:80-129.

Gilbert CD, Wiesel TN (1985) Intrinsic connectivity and receptive field properties in visual cortex. Vision Res 25:365-374.

Heggelund $P$ (1981) Receptive field organization of simple cell in cat striate cortex. Exp Brain Res 42:89-98.

Henry GH (1977) Receptive field classes of cells in the striate cortex of the cat. Brain Res 133:1-28.

Henry GH, Goodwin AW, Bishop PO (1978) Spatial summation of 
responses in receptive fields of single cells in cat striate cortex. Exp Brain Res 32:245-266.

Hirsch JA, Gilbert CD (1991) Synaptic physiology of horizontal connections in the cat's visual cortex. J Neurosci 11:1800-1809.

Hubel DH, Wiesel TN (1962) Receptive fields, binocular interaction and functional architecture in the cat's visual cortex. J Physiol (Lond) 160:106-154.

Jones JP, Palmer LA (1987) The two-dimensional spatial structure of simple receptive fields in cat striate cortex. J Neurophysiol 58:11871211.

Kato H, Bishop PO, Orban GA (1978) Hypercomplex and simple/ complex cell classifications in cat striate cortex. J Neurophysiol 41: $1071-1095$.

Lankheet MJM, Molenaar J, Van de Grind WA (1989) The spike generating mechanism of cat retinal ganglion cells. Vision Res 29: $505-517$

Lee BB, Cleland BG, Creutzfeldt OD (1977). The retinal input to cells in area 17 of the cat's cortex. Exp Brain Res 30:527-538.

Maffei L, Fiorentini A (1976) The unresponsive regions of visual cortical receptive fields. Vision Res 16:1131-1139.

Martin KAC (1988) From single cells to simple circuits in the cerebral cortex. Q J Exp Physiol 73:637-702.

Miller KD, Chapman B, Stryker MP (1989) Visual responses in adult cat visual cortex depend on $N$-methyl-D-aspartate receptors. Proc Natl Acad Sci USA 86:5183-5187.

Nelson JI, Frost BJ (1978) Orientation-selective inhibition from beyond the classical visual receptive field. Brain Res 139:359-365.

Palmer LA, Davis TL (1981) Comparison of responses to moving and stationary stimuli in cat striate cortex. J Neurophysiol 46:277-293.

Pei X, Volgushev M, Vidyasagar TR, Creutzfeldt OD (1991) Wholecell recording and conductance measurements in cat visual cortex in vivo. Neuroreport 2:485-488.

Pei X, Volgushev M, Vidyasagar TR, Creutzfeldt OD (1992) Excitatory and inhibitory input fields of simple cells in cat's striate cortex. In: Abstracts of the 15th annual meeting of the European Neuroscience Association, p 261. New York: Oxford UP (on behalf of The European Neuroscience Association).

Rodieck RW (1965) Quantitative analysis of cat retinal ganglion cell response to visual stimuli. Vision Res 5:538-601.

Sakmann B, Neher E, eds (1983) Single-channel recording. New York: Plenum.

Shevelev IA, Sharaev GA (1981) Dynamics of orientation tuning of cat visual cortical neurons. Neurophysiology 13:315-320.
Shou TD, Leventhal AG (1989) Organized arrangement of orientation-sensitive relay cells in the cat's dorsal lateral geniculate nucleus. J Neurosci 9:4287-4302.

Sillito AM (1975) The contribution of inhibitory mechanisms to the receptive field properties of neurons in the striate cortex of the cat. J Physiol (Lond) 250:305-329.

Sillito AM, Kemp JA, Milson JA, Berardi N (1980) A rc-cvaluation of the mechanisms underlying simple cell orientation selectivity. Brain Res 194:517-520.

Soodak RE (1986) Two-dimensional modelling of visual receptive fields using gaussian subunits. Proc Natl Acad Sci USA 83:9259_ 9263.

Tanaka K (1983) Cross-correlation analysis of geniculo-striate neuronal relationships in cats. J Neurophysiology 49:1303-1318.

Ts'o DY, Gilbert CD, Wiesel TN (1986) Relationships between horizontal interactions and functional architecture in cat striate cortex as revealed by cross-correlation analysis. J Neurosci 6:1160-1170.

Tsumoto T, Creutzfeldt OD, Legéndy CR (1978) Functional organization of the corticofugal system from visual cortex to lateral geniculate nucleus in the cat (with an appendix on geniculo-cortical monosynaptic connections). Exp Brain Res 32:345-364.

Tsumoto T, Eckart W, Creutzfeldt OD (1979) Modification of orientation sensitivity of cat visual cortex neurons by removal of GABAmediated inhibition. Exp Brain Res 34:351-365.

Vidyasagar TR (1987) A model of striate response properties based on geniculate anisotropies. Biol Cybern 57:11-23.

Vidyasagar IR (1989) Can subcortical orientation bases from the basis for orientation sensitivity of striate cortical neurons. In: Seeing contour and colour (Kulikowski JJ, Dickinson CM, Murray IJ, eds), pp 66-74. Manchester: Pergamon.

Vidyasagar TR, Urbas JV (1982) Orientation sensitivity of cat LGN neurons with and without inputs from visual cortical area 17 and 18 . Exp Brain Res 46:156-169.

Volgushev M, Pei X, Vidyasagar TR, Creutzfeldt OD (1992) Postsynaptic potentials in cat visual cortex: dependence on polarization. Neuroreport 3:679-682.

Volgushev M, Pei X, Vidyasagar TR, Creutzfeldt OD (1993) Excitation and inhibition in orientation selectivity of cat visual cortex neurons revealed by whole-cell recordings in vivo. Vis Neurosci 10: 1151-1155. 